\title{
INTERVENCIÓN EN LA CATEDRAL DE LA PLATA, ARGENTINA
}

\author{
(INTERVENTION IN THE CATHEDRAL OF LA PLATA, ARGENTINA)
}

Guillermo R. García, Arquitecto

Fecha de recepción: 23-IV-99

\section{RESUMEN}

La iglesia Catedral, el último de los edificios fundacionales inconclusos de la ciudad de La Plata, capital de la Provincia de Buenos Aires, presentaba importantes desajustes. Dada su magnitud y complejidad fue necesario elaborar un plan de intervención que resolviera integralmente dichas patologías y, simultáneamente, permitiera completar el Templo, de acuerdo al anteproyecto elaborado en 1885.

\section{SUMMARY}

The church Cathedral, the last of the foundational buildings unconcluded of the city of La Plata, capital of the County of Buenos Aires, presented important problems. Given their magnitude and complexity was necessary to elaborate an intervention plan that solved this pathologies integrally and simultaneously it allowed the termination of the Temple, according to the preliminary design elaborated in 1885.

\section{La Catedral de las pampas}

Este artículo quiere ser testimonio del proceso metódico que llevamos adelante en la Catedral platense, comunicar, a manera de cápsula espacio - temporal, el cómo y los por qué de esta intervención.

\section{Yaque...}

Partimos por considerar a la creatividad humana abierta a la realidad, al encuentro, que incorpora las realidades del entorno y la tradición en su proceso de intervención, proceso que genera experiencias y se inserta en un ámbito particular, al que enriquece mejorando la calidad de vida y humanizándolo con sus productos.

\section{El monumento y su memoria}

Cercana ya la fecha de la Fundación de la Ciudad de La Plata, capital de la Provincia de Buenos Aires, República Argentina, en 1881 se procede a la apertura del Concurso para la presentación de planos y presupuestos destinados a la construcción de edificios públicos, entre ellos, la Catedral.

(c) Consejo Superior de Investigaciones Científicas

Licencia Creative Commons 3.0 España (by-nc)
El Concurso tuvo una amplia difusión; entre los países que presentaron proyectos, figuraron: Francia, Alemania, Inglaterra, Bélgica, Uruguay, Chile y Argentina.

Como requisito fundamental se pedía que el templo revistiera carácter monumental.

La comisión del Concurso rechazó todos los planos propuestos para el templo, por no ajustarse a las bases del mismo.

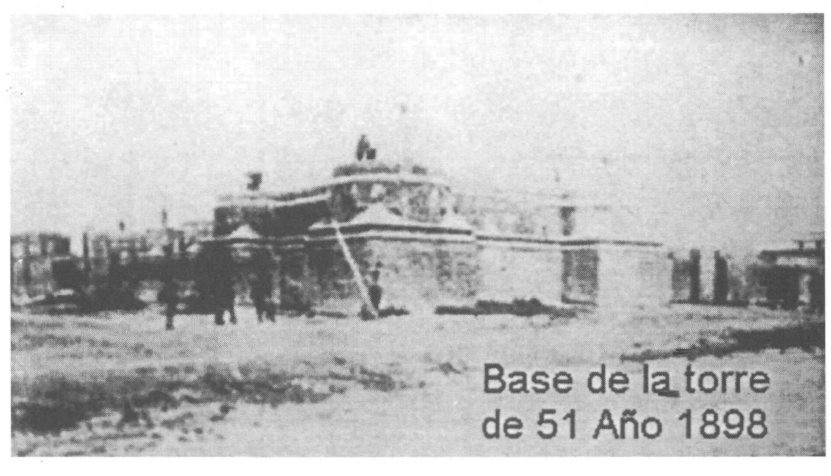

Foto 1

http://informesdelaconstruccion.revistas.csic.es 


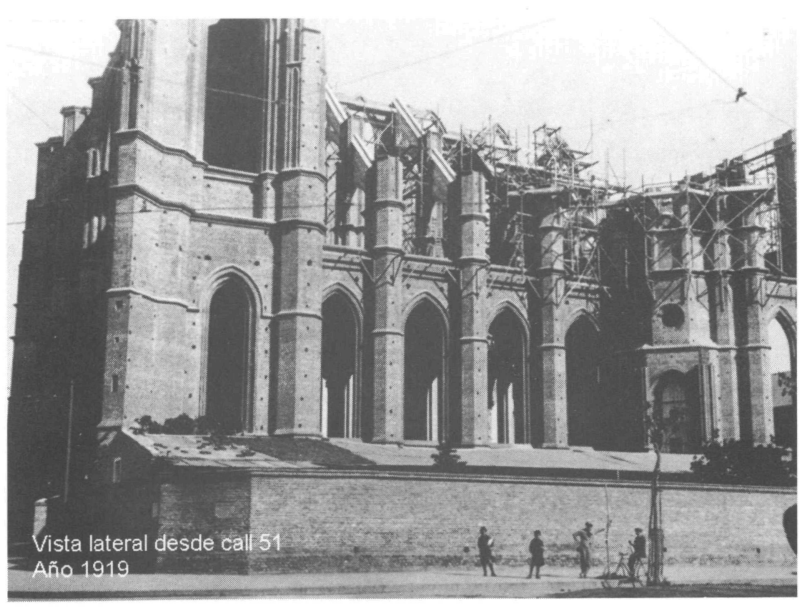

Foto 2

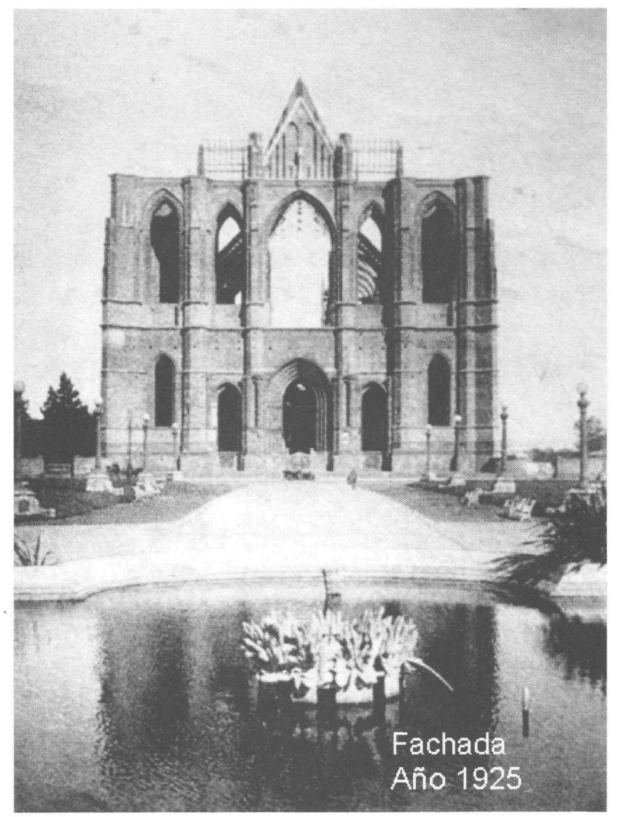

Foto 3

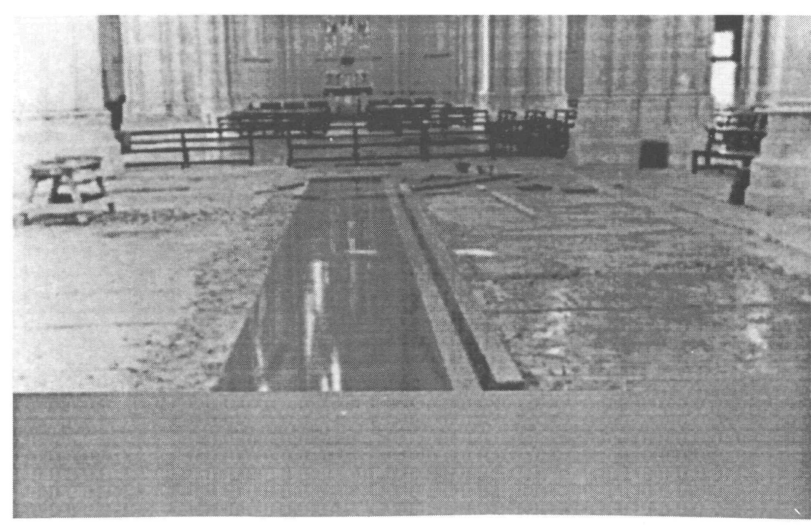

Foto 4

(c) Consejo Superior de Investigaciones Científicas Licencia Creative Commons 3.0 España (by-nc)
La naturaleza -decía Dardo Rocha, fundador de La Plata-, nos enseña que las formaciones duraderas sólo se elevan con gran esfuerzo y en largo tiempo y así, las obras de los hombres, para que duren, necesitan ser a imagen de ellos, hechas con dura labor y esfuerzo infatigable... Y es así como se advierte , por ejemplo, que la determinación primitiva de dotar a La Plata de un templo católico de alguna importancia evoluciona hacia el logro de una catedral de proporciones poco comunes.

Se encarga entonces al Departamento de Ingenieros de la Provincia, la elaboración de un nuevo proyecto. Correspondió al entonces Director de Obras Públicas, Ingeniero Pedro Benoit, la presentación del proyecto de obra y al Arquitecto alemán Ernesto Meyer, los dibujos definitivos, colaborando, con todos ellos, el Arquitecto Emilio Coutaret.

El proyecto original tenía tres torres, una sobre la bóveda del crucero y dos laterales, en la fachada, que podían visualizarse desde la "cofa" de los barcos que llegaran al Río de la Plata, tal como lo imaginara el Ingeniero Pedro Benoit. El 16 de noviembre de ese año, las autoridades civiles y religiosas, reunidas en la manzana fijada para la construcción del templo, procedieron al trazado del eje de la Catedral, cuya dirección era perpendicular a la calle 14 .

Los trabajos acabarían demorándose, al no contar con las erogaciones fiscales que demandaba tamaño proyecto. Pero, durante 1898, Monseñor Mariano Espinosa impulsó las obras de la Catedral. Comenzaron a levantarse los muros perimetrales que, a nivel del suelo, tenían $1,80 \mathrm{~m}$ de espesor y se completaron las bases de ladrillos para las columnas de las naves y del crucero.

El primer contrato de construcción de arcos invertidos y colocación de columnas del crucero, data de 1906. En 1909 se inició la construcción de las bóvedas de hormigón armado y cimientos del vestíbulo, así como los arcos sobre columnas. Durante 1912 se impulsaron, nuevamente, las obras, con el apoyo de las autoridades civiles y religiosas y de la Legislatura Provincial. Se contrató mano de obra especializada, de albañiles y picapedreros criollos, italianos, franceses y alemanes, que comenzaron los trabajos de labrado de las columnas, utilizando piedra- traída en bloques- desde la cantera de Punta Mogotes.

Con renovado impulso se sucedieron, año tras año, innumerables tareas: se construyeron los arcos de los vestíbulos (1913); la elevación de muros y cornisa del frente (1915); la construcción de arbotantes, mampostería, cornisa interior y vestíbulo (1917); columnas del crucero, columnas, bases y capiteles (1919); se elevaron los muros de la nave central, tímpano,_techo metálico (1920); comenzaron a colocarse las cabriadas principales del techo de la nave central y del transepto o crucero,

http://informesdelaconstruccion.revistas.csic.es 
estructura de hormigón armado para sostener el piso (1925); el rosetón, ventanal central del frente, se instaló en 1928; también la estructura metálica de la techumbre (1930) y, en 1931, se incorporaron cornisas, parapetos y desagües.

En 1932 se inauguró la Catedral, en el marco del Cincuentenario de la fundación de la Ciudad de La Plata.El 19 de noviembre del mismo año se celebró el primer oficio religioso, con la asistencia de autoridades nacionales y provinciales, entre ellas, el Presidente de la Nación, Gral. Agustín P. Justo.

El techo de cobre de la linterna y cruz de la aguja se instalaron entre 1933 y 1935 , mientras se realizaba el revoque interno y externo del mismo sector, en símil piedra. Entre los años 1936 y 1940 se ejecutaron los revestimientos de las bóvedas y esculturas de santos, ubicados en los nichos del tambor; contrapiso del ábside; los capiteles de las columnas; las filigranas de piedra, ubicadas en el trascoro y trasaltar; se colocaron los primeros vitrales de la casa Zetler de Munich, Alemania; se instaló el trono arzobispal; la sillería del coro de canónigos y los confesionarios.

El 19 de noviembre de 1940 se trasladaron los restos del fundador y su esposa a la cripta instalada en el subsuelo de la Catedral. Al año siguiente se colocó el piso, de granito rosado de Olavarría, con junta gris de San Luis y negro de Balcarce. Finalmente, superadas las dificultades de la Segunda Guerra Mundial, en 1947, comenzaron a colocarse vitrales franceses de las casas Lorin y Maunejean.

En 1944, el Prof. José María Rey fue ungido como historiador de la ciudad, coronando una empresa, iniciada en 1932, con la publicación del librơ La Nueva Capital. En la edición de otra de sus obras, Tiempos y Fama de La Plata, aparece el título "LA CATEDRAL INCONCLUSA" $\mathrm{y}$, entre sus párrafos, se destacan: "la ciudad tiene en la Catedral inconclusa una prueba externa de la grandeza prevista por sus fundadores, que el platense aprecia desde extramuros con no poco regocijado orgullo localista. Y cuando las torres simétricas frontales que faltan construir hiendan sus agujas en el éter, a los 120 metros de altura sobre la acera del templo, los viajeros y paseantes de los caminos suburbanos y rurales del partido experimentarán maravillados la misma fluencia emotiva que embelleció la frialdad de aquellos números que ilustraron el juicio de los dignos constructores de la ciudad armoniosa". Estas líneas fueron publicadas en 1957.

\section{Los trabajos de conservación y puesta en valor}

A mediados de 1995, con el Consorcio Obras Catedral iniciamos las obras de conservación y puesta en valor del templo, colaborando con la Dirección de Arquitectura del

(c) Consejo Superior de Investigaciones Científicas

Licencia Creative Commons 3.0 España (by-nc)

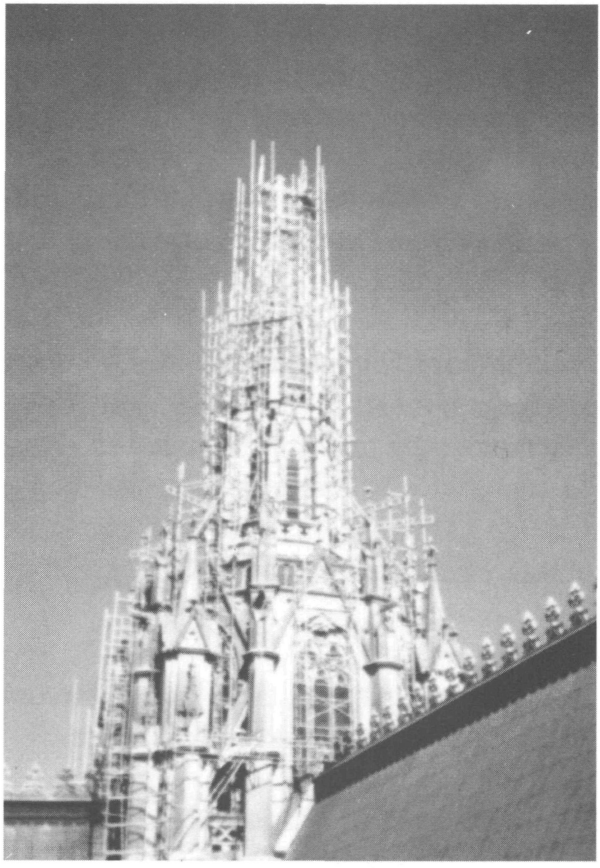

Foto 5

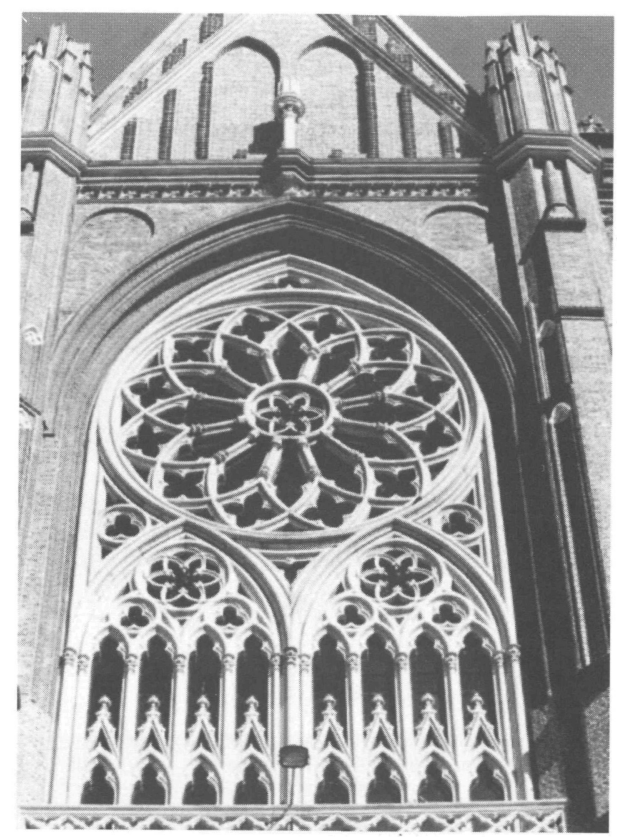

Foto 6

Ministerio de Obras y Servicios Públicos en el diseño de planes de intervención puntuales, su ajuste a standares internacionales, investigación histórica, confrontación con otros ejemplos a nivel internacional, selección de técnicas y materiales compatibles con la Iglesia Catedral de La Plata.

Así, se inician las obras en el exterior del Templo, según los siguientes objetivos:

http://informesdelaconstruccion.revistas.csic.es 
1.- Absoluto respeto del Monumento y voluntad explícita de no alterar su imagen de fábrica de ladrillos, referente para los habitantes de La Plata.

2.- Revertir el proceso de deterioro de la mampostería y otros subsistemas -ornamentos, carpinterías, vitrales, etc.a través de la restauración de los mismos, respetando textura y color originales.

3.- Utilización de técnicas artesanales y herramientas similares a las originales, combinadas con productos de última generación, que garantizan unidad en el tratamiento de los materiales y máxima vida útil con mínimo mantenimiento. Todas las intervenciones realizadas no son agresivas y permiten un correcto envejecimiento del conjunto.

4.- Las medidas de seguridad, tanto para el personal como para el edificio, son atendidas puntualmente.

5.- Todas las decisiones adoptadas se basan en una profunda investigación histórico-documental .

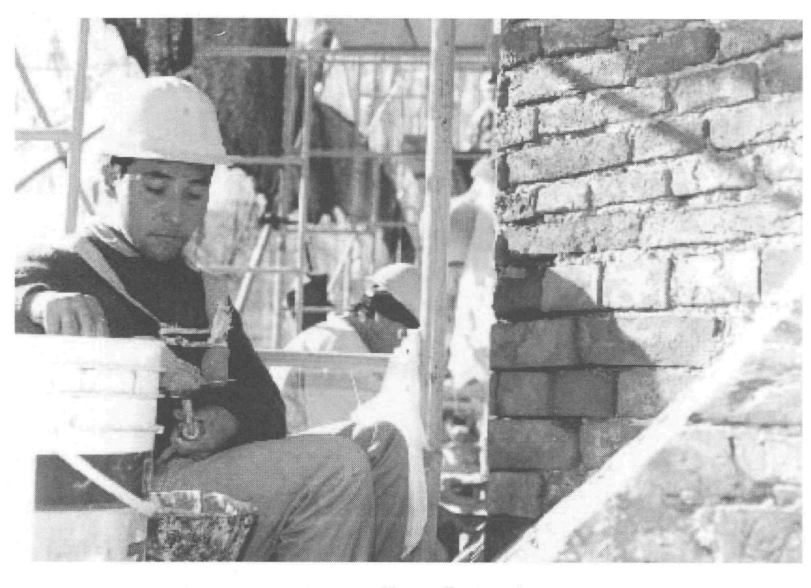

Foto 7

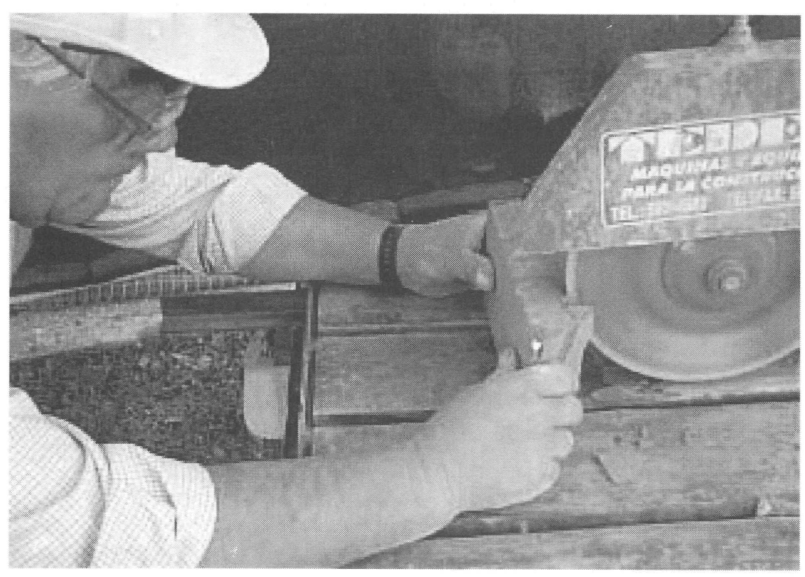

Foto 8

(c) Consejo Superior de Investigaciones Científicas Licencia Creative Commons 3.0 España (by-nc)

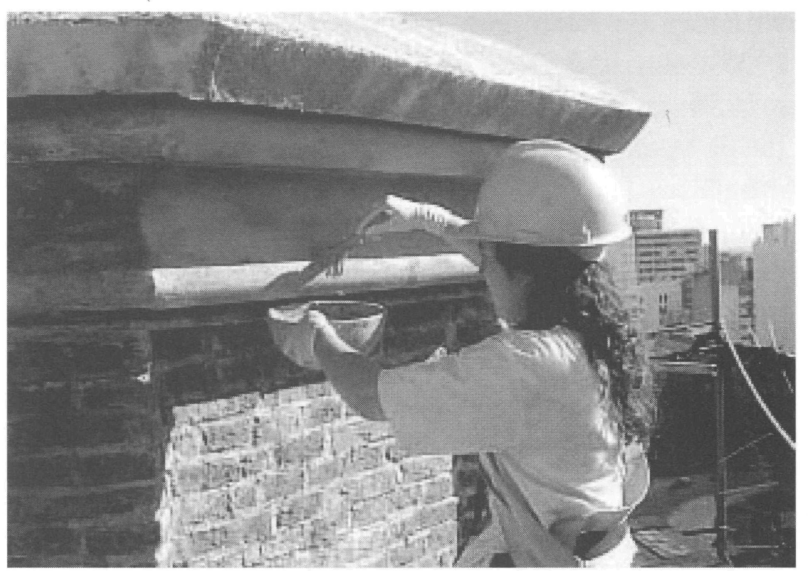

Foto 9

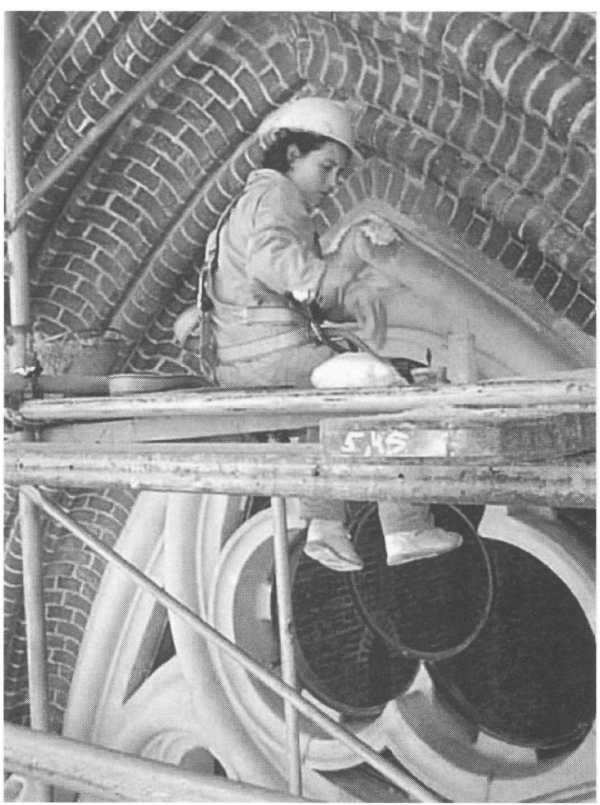

Foto 10

6.- Las intervenciones puntuales y cada pieza recolocada in situ son fechadas a través de plástico inalterable, según exigentes criterios de datación.

Para cumplir con las exigencias planteadas en los objetivos fue necesario el concurso de importantes proveedores, nacionales y del exterior, en cuanto a materiales y equipos.

Además, en cuanto al personal,éste debió ser seleccionado y entrenado en técnicas compatibles con la obra. Fue necesaria incluso la fabricación de herramientas.

Antes de generalizar cualquier area, el criterio es realizar pruebas y ajustarlas gradualmente, hasta obtener los resultados esperados; luego, se autoriza la ejecución.

http://informesdelaconstruccion.revistas.csic.es 


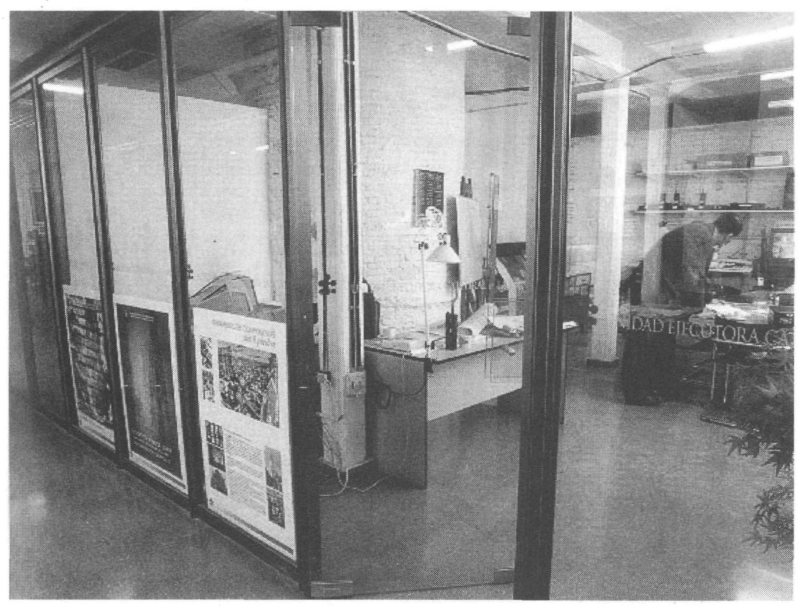

Foto 11

\section{Un equipo en acción}

La UnidadEjecutora Catedral de La Plata fue creada por la Ley Provincial 11.861 en el mes de octubre de 1996, como resultado de una iniciativa del Poder Ejecutivo de la Provincia de Buenos Aires, respaldada, totalmente, por ambas cámaras de la Legislatura. El objetivo de la UnidadEjecutora es llevar adelante las tareas de conservación, restauración, puesta en valor y completamiento del edificio Catedral de La Plata, Templo Mayor de la capital de la Provincia de Buenos Aires, inscripto en la nave central de la Basílica de San Pedro, por su tamaño monumental, que la ubica entre las más importantes del mundo.

De este modo, el Gobierno de la Provincia de Buenos Aires hizo suya la propuesta de la Fundación Catedral de La Plata de incluir, en el Plan de Rejerarquización de la Ciudad, la puesta en valor del Edificio Catedral.

La Unidad Ejecutora ha resuelto dividir el tratamiento del edificio en tres licitaciones: la primera de estas obras, consiste en la conservación, restauración y puesta en valor de la envolvente edilicia de la Catedral; luego los trabajos de micropilotaje y refuerzo de las cimentaciones de las torres principales $\mathrm{y}$, por último, el completamiento del edificio.

El equipo técnico de la U.E.C. comienza por diseñar el ámbito de trabajo, la sede de la Unidad, en el mismo subsuelo del templo, así como la estrategia de intervención y las herramientas tecnológicas necesarias para cumplir eficientemente el desafío que se planteaba.

\section{I) Marco de referencia}

\section{El signo de nuestro tiempo}

Las técnicas contemporáneas permiten optimizar el diseño de planes de intervención en contextos patrimoniales, incorporando nuevas herramientas que, aunque, originalmente fueran diseñadas para otras funciones, bien pueden incorporarse a la gestión del patrimonio.

\section{Tecnología}

Los avances tecnológicos en materias relevantes (fotografías satélites, aerofotografías), junto al procesamiento digital del PC, permiten, a través de imagen virtual, monitorizar las distintas áreas de la ciudad.

El posterior procesamiento, a través de maquetas digitales, permiten modelizar las posibles decisiones sobre el sitio y analizar el grado de impacto antes de su realización.

La informática contemporánea y el diseño de programas complejos a un costo razonable logran eficiencia y velocidad en el planteamiento de propuestas urbanas, ya que pueden manejarse gran cantidad de datos de forma simultánea.

Por último, alta tecnología y recursos humanos, entrenados para su operación, generan una economía de recursos y respuestas rápidas a problemas complejos.

Otra de las ventajas de la tecnología es la de disponer de elementos gráficos o videográficos que permiten desarrollar modelos de comunicación para entregar a los medios de difusión. De esta forma se completa el circuito y la población se informa, a través de gráficos, infografias o imágenes en movimiento, de las propuestas que se formulan para la puesta en valor o intervención.

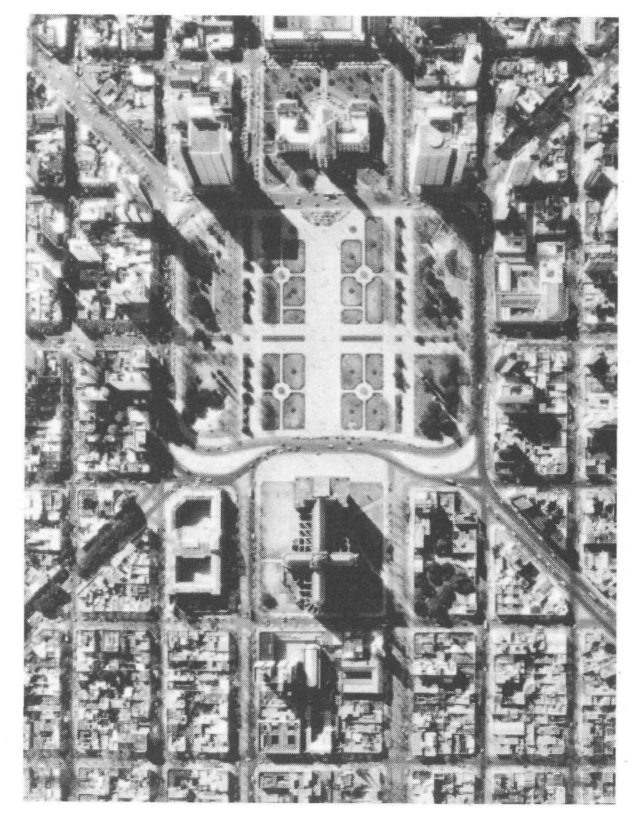

Foto 12

http://informesdelaconstruccion.revistas.csic.es 


\section{Equipo multidisciplinar}

Se propone tratar de definir el perfil del hombre actual, el verdadero hombre post-moderno, hombre que debe trabajar en equipo, atento a la riqueza, que, para nuestra vida, significan los seres de nuestro entorno.

Realizar trabajos que fomenten el encuentro con personas y personalidades de distintas disciplinas, que aportan al equipo los valores que rigen su actividad profesional.

El plan para la intervención de conjuntos monumentales, a nuestro entender, debe surgir de un equipo multidisciplinar que se apoye en las nuevas tecnologías de gestión, relevamiento, supervisión y control de intervención.

La conformación del entorno de trabajo se basa en una red de computadoras vinculadas entre sí y en tiempo real, a través de E-mail, con el estudio de los asesores externos.

Nuestro método es integral y, desde el inicio, apunta a la eficiencia y economía de recursos. Además, incorpora nuevas tecnologías del tratamiento de la documentación escrita, gráfica, fotográfica, etc., basado en soporte digital.

\section{Encuadre metodológico}

A los efectos de definir el proyecto de intervención, entendemos que habrán de realizarse diversas tareas de observación y reconocimiento general, en base al arreglo de deterioros en intervenciones anteriores, apoyado por material geotopográfico, fotogramétrico, fotográfico y registro videográfico, en orden a la determinación de las técnicas de intervención.

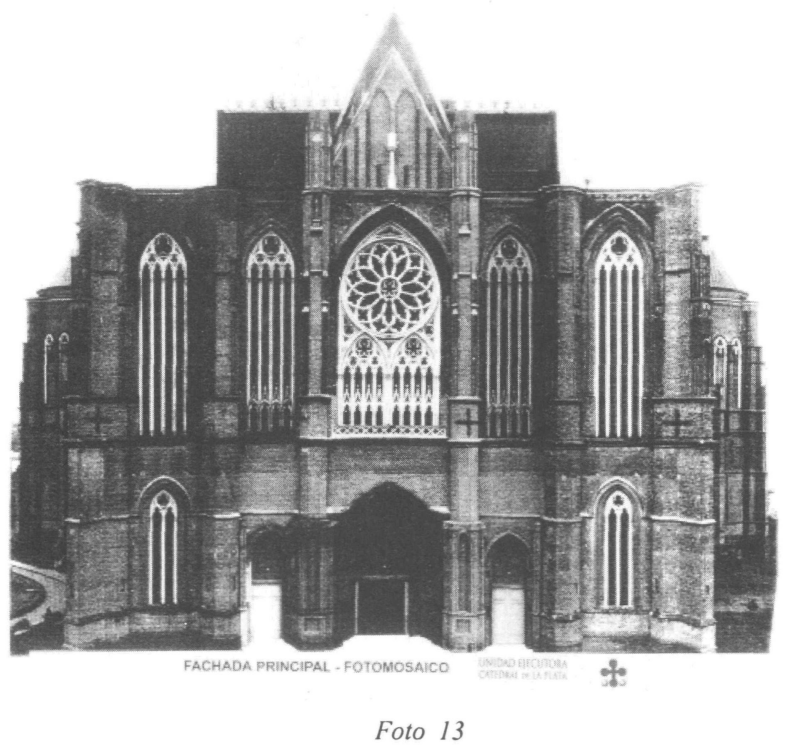

(c) Consejo Superior de Investigaciones Científicas Licencia Creative Commons 3.0 España (by-nc)

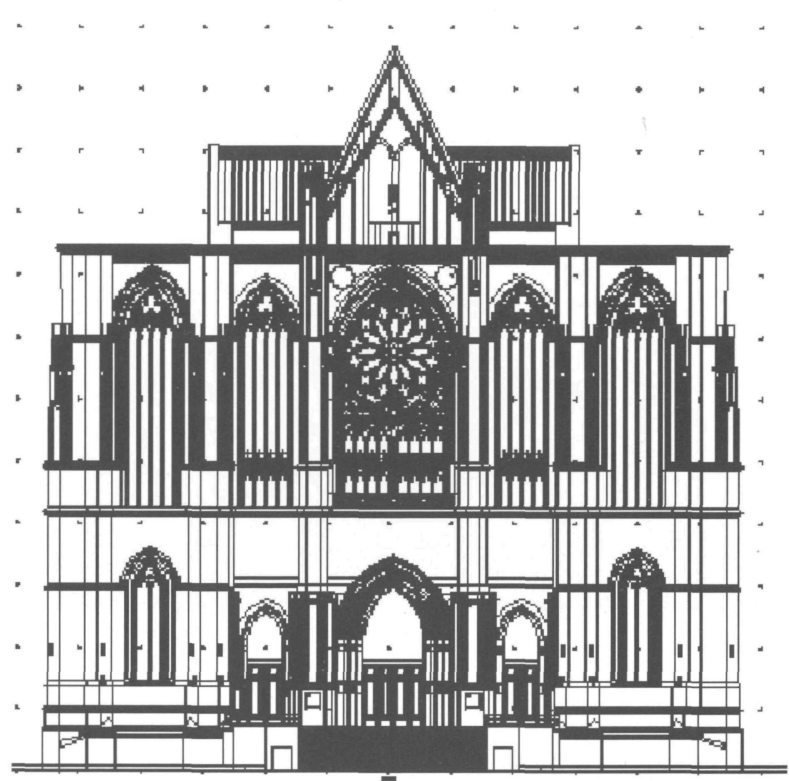

Foto 14

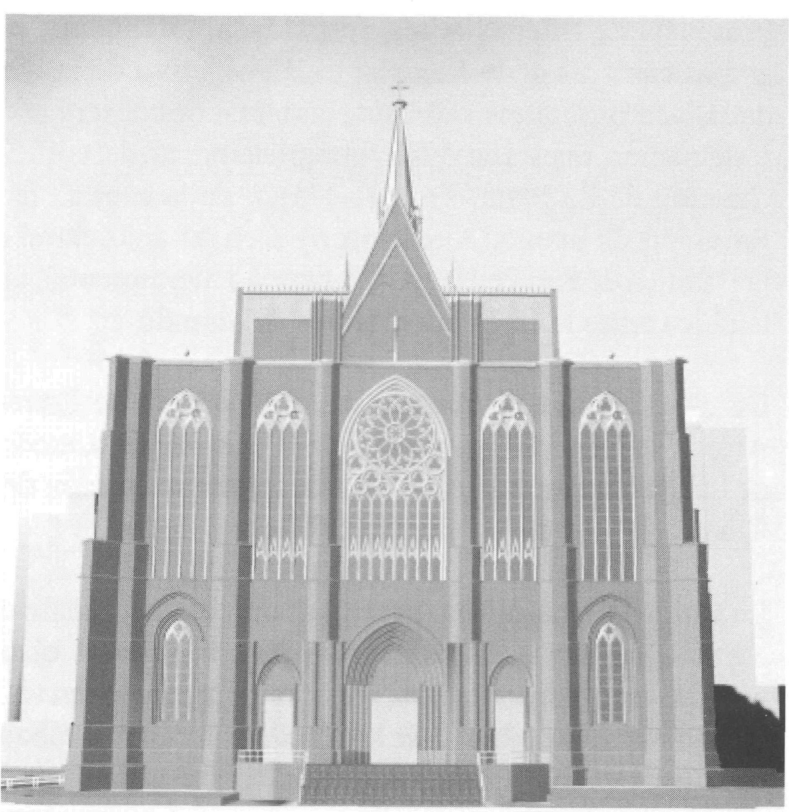

Foto 15

\section{II) Recolección de datos previa al inicio de tareas}

Reunión de planos, escritos, fotos, etc., para reconstruir fielmente el historial del sitio, así como las distintas modificaciones y ajustes que se han verificado en el transcurso de la obra.

- La documentación rescatada fue tratada en base a ciertos criterios, los cuales permitieron la identificación y el fichaje del origen e inventario de la fuente documental. http://informesdelaconstruccion.revistas.csic.es 


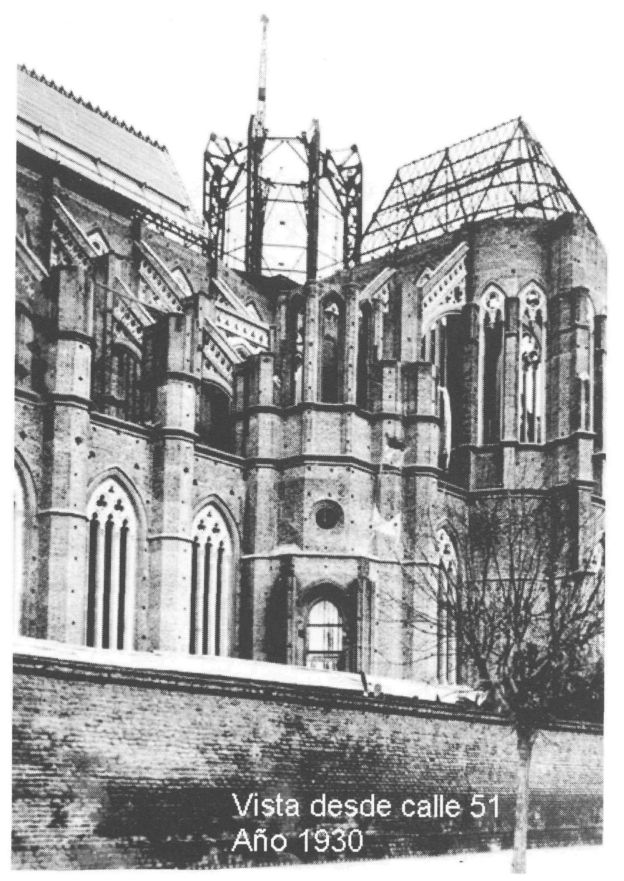

Foto 16

- La manipulación de originales se realiza teniendo en cuenta estrictas pautas de conservación del material.

- Se procedió, en primera instancia, a realizar copias de respaldo, reproduciendo, en base poliéster, fotografías y escaneo digital, según el documento.

- Tanto documentos originales como copias fueron acondicionados convenientemente, según parámetros técnicos de conservación y seguridad.

- Se realizó un cronograma de obras ejecutadas, vinculando la documentación obtenida con las distintas etapas de obra, con el fin de lograr un efecto dinámico, que ilustre los distintos ajustes que el edificio ha sufrido en el transcurso de su historia.

- El rigor técnico con que se realizó esta etapa garantizó la corrección al elaborar el proyecto de intervención y los pliegos específicos para la obra.

\section{III) Diseño de Intervención}

El equipo técnico comenzó por diseñar el ámbito de trabajo, así como la estrategia de intervención y las herramientas tecnológicas necesarias para cumplir, de manera eficiente, el desafío planteado.

Además, se desarrolló la documentación en forma digital, a efectos de incluirla en soporte CD, que permite a los interesados el compulsar la documentación, acceder (c) Consejo Superior de Investigaciones Científicas Licencia Creative Commons 3.0 España (by-nc) fácilmente a la totalidad de la misma, así como realizar consultas por correo electrónico.

Para la correcta intervención, el estudio detallado se resuelve a través de la combinación de técnicas de última generación, especialmente ajustadas a la escala del edificio. Entre ellas, podemos mencionar:

A).- Investigación Histórica, realizada por diferentes especialistas, barriendo sistemáticamente todas las fuentes, obteniendo documentos originales, testimonios fotográficos y videográficos. Después de catalogar y realizar copias de respaldo, se procedió a digitalizar el material, a través de: scaneo de fotos con alta resolución, vectorización y escalado de planos y edición de vídeo.

Resuelta la reconstrucción y posterior digitalización del material original en formato Autocad, se realizaron modelos o maquetas electrónicas de la propuesta.

B).- Geotopografía y Fotogrametría arquitectónica: Para estudiar, de manera fiel, el monumento se procedió a la combinación de técnicas de alta precisión en el levantamiento de edificios existentes, apelando a estaciones computadas, medidores ultrasónicos,

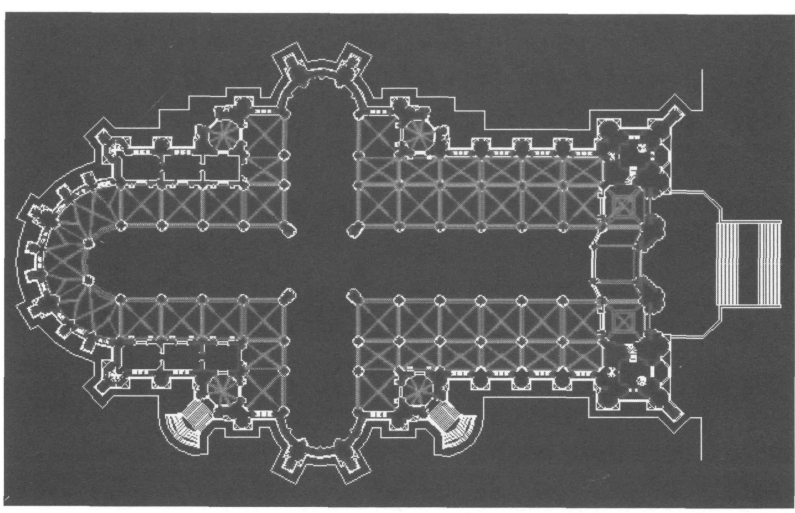

Foto 17

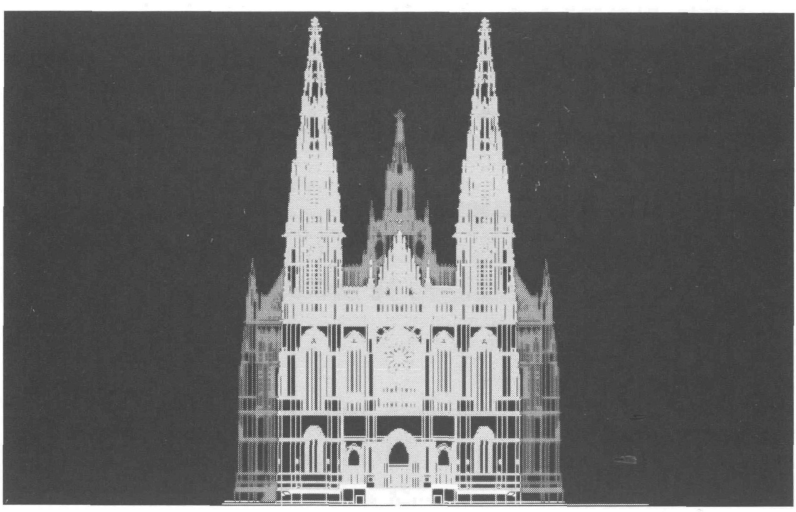

Foto 18

http://informesdelaconstruccion.revistas.csic.es 


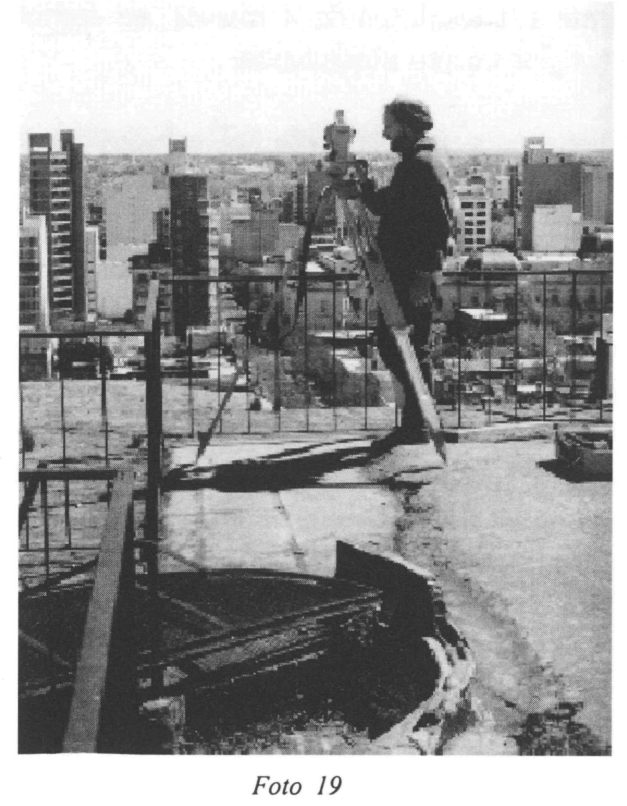

plataformas hidroelevadas. La restitución fotogramétrica, basada en mediciones geotopográficas, se realizó, en forma magnética, a través de tableta digitalizadora y en sistema Autocad. Luego, fue posible la formulación de la maqueta electrónica del edificio.

C).- Análisis y ensayos : El trabajo se completó con la toma de muestras de los distintos subsistemas que componen el edificio, a efectos de determinar composición, patologías y resistencia de los materiales originales. Para ello se contó con el auxilio de laboratorios de probada experiencia.

\section{Digitalización de planos originales}

La documentación planimétrica del proyecto de 1885 fue realizada en Autocad vectorialmente, vía tableta digitalizadora. Este método es el adoptado, al obtenerse del proceso entidades editables y mensurables, que permitieron comparaciones con el modelo matemático resultante del estudio fotogramétrico - geotopográfico y, además, corrige proyectivamente la desviación irregular de las copias usadas, restituyendo las medidas originales con la mayor precisión posible y con una tolerancia de, más o menos, $0,0002 \mathrm{~m}$, en escala 1: 100 .

\section{Maquetas electrónicas}

Las geometrías complejas se sustentan en la interacción de formas puras.

Así, el edifício o conjunto puede entenderse como la adición, substracción e intersección de prismas, cuyo resultado es un volumen de extrema complejidad, al que se le adiciona la ornamentación.
El primer paso es analizar la documentación, descubriendo las estrictas relaciones matemáticas subyacentes que articulan el diseño.

Entendido el edificio de este modo, es posible transportar la traza geométrica a sistemas $\mathrm{CAD}$, mediante el cual, por medio de operaciones de adición y sustracción entre las geometrías antes descritas se desarrolla una "maqueta electrónica."

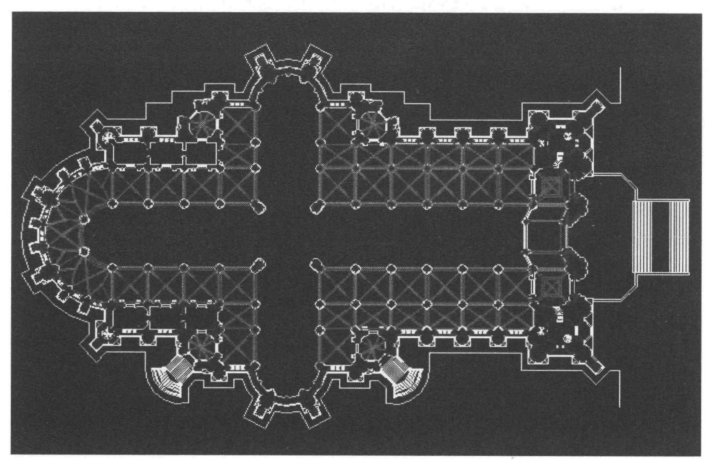

Foto 20

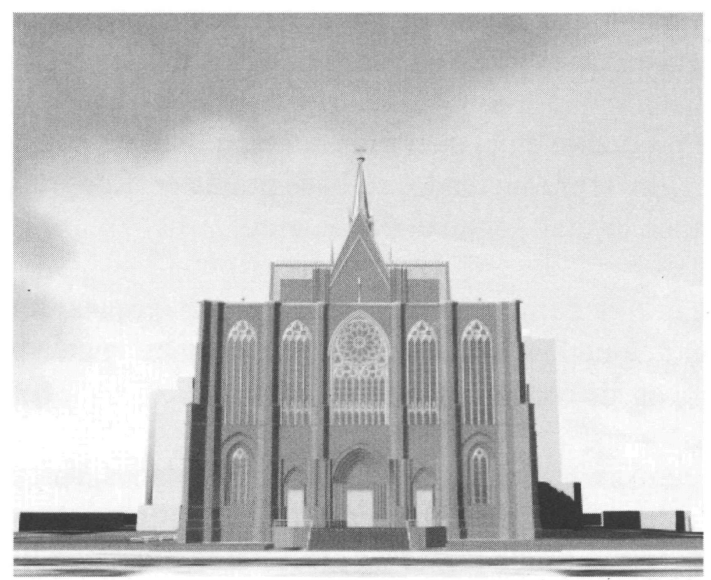

Foto 21

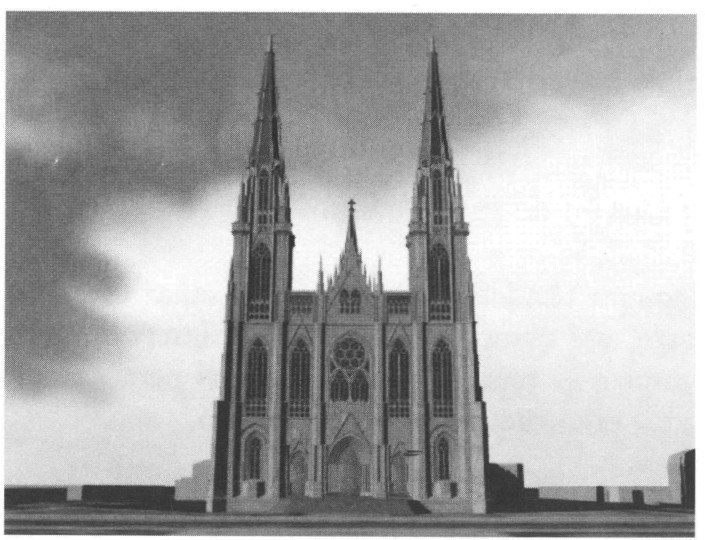

Foto 22

http://informesdelaconstruccion.revistas.csic.es 


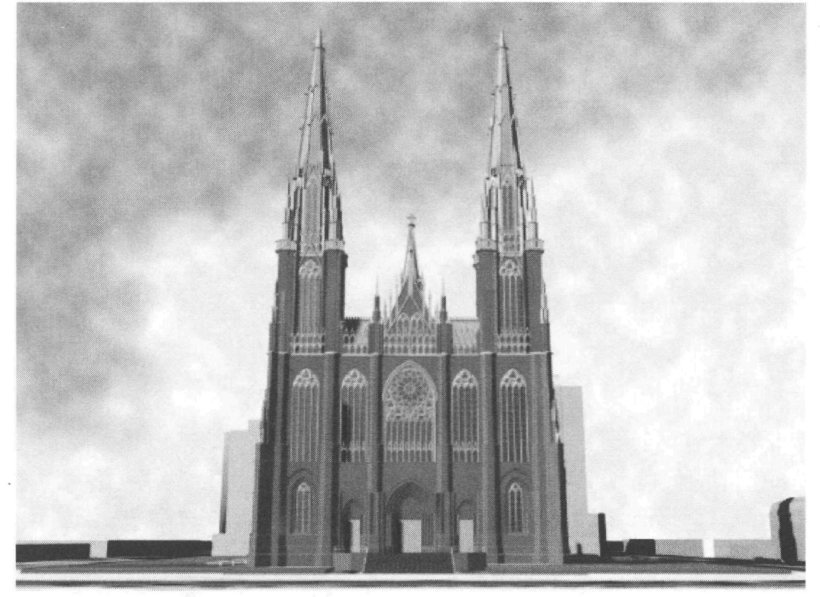

Foto 23

Después de esta evaluación, se transportan a Autocad los distintos datos (para la generación geométrica en forma modular), construyéndose tridimensionalmente -y por separado- los elementos repetitivos del edificio. En un paso posterior se unieron, como un rompecabezas, todos los elementos, dando por resultado la envolvente del conjunto.

La última etapa es la "animación" de la maqueta electrónica, para lo que se diseñaron, de forma especial, los materiales; con el fin de tratar la superficie de los elementos correspondientes, se utilizaron iluminación, cámaras..., obteniéndose como resultado unas imágenes muy reales.

Un proceso similar, pero partiendo de la restitución fotogramétrica en formato digital, se realizó para la elaboración de una maqueta electrónica del edificio actual.

\section{IV ) Control de gestión}

Decidimos que las empresas adjudicatarias, conducidas por el equipo técnico, realizasen un registro, a través de cámara digital ( DV Cam ), general y de detalle, de las distintas áreas de intervención, a efectos de documentar la situación previa, la evolución de los trabajos y estado final. El soporte es un programa interactivo en CD Rom, que se ejecuta desde el sistema operativo y podrá basarse en una cuadrícula o red virtual, de modo que cubra la totalidad del monumento intervenido.

Además, a los efectos de una efectiva supervisión técnica "on line ", se indicó a las empresas contratistas la necesidad de instalar, en cada área en que se estén realizando los trabajos, cámaras de vídeo, con el fin de registrar las tareas desarrolladas. Éstas se vinculan por cable coaxil a la oficina técnica, desde donde se monitorizan y dirigen a control remoto, en forma continua. Sumando una placa digitalizadora de vídeo y una grabadora, se pueden registrar las tareas observadas.

(c) Consejo Superior de Investigaciones Científicas

Licencia Creative Commons 3.0 España (by-nc)

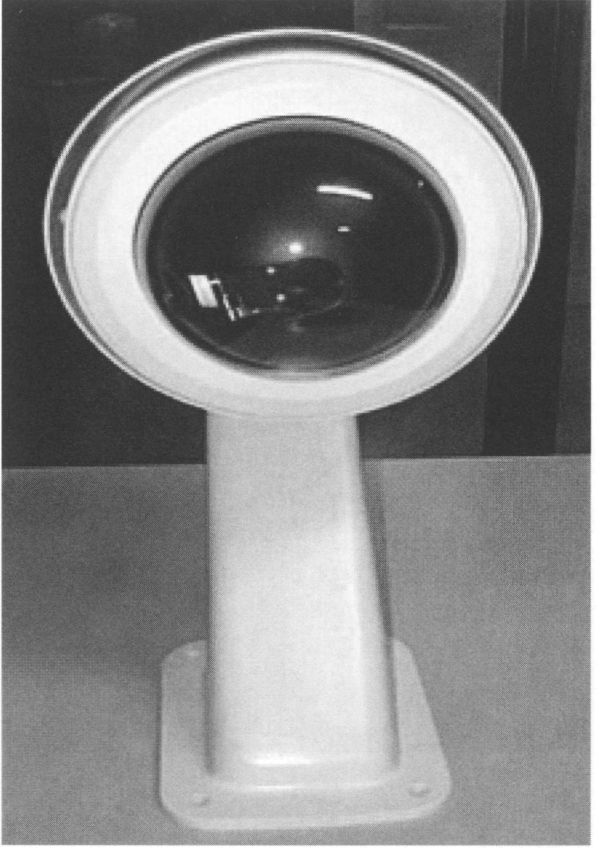

Foto 24

\section{Documentación en soporte CD}

Las nuevas tecnologías multimedia, junto a la utilización de $\mathrm{CD}$, permiten el almacenamiento y la difusión de gran cantidad de información. Por ese motivo, fueron elegidas por nuestro equipo técnico, para editar los pliegos de las licitaciones públicas correspondientes a las distintas obras.

La arquitectura del $\mathrm{CD}$, fue elaborada por un equipo multidisciplinar, que estableció las siguientes pautas:

Facilidad de acceso a la diversa documentación que contiene el CD, aun para operadores inexpertos.

No ser necesario poseer soft diferenciado para su visualización. Sólo se requiere Windows 95.

Así, se diseñó un producto con autoayuda gráfica e iconos en pantalla y que aparece en forma automática al colocar el CD en la unidad CD ROM. Además, las instrucciones básicas se expresan en castellano e inglés.

El contenido, a modo de ejemplo, es el siguiente:

Maquetas electrónicas, de acuerdo al proyecto original, el edificio actual y el proyectado, restituidos en CAD, renderizados en 3D y transferidos a formato AVI, para funcionar en Windows 95.

Vídeo que relata la historia del sitio en formāto AVI.

Fotos históricas que permiten conocer el proceso de construcción.

http://informesdelaconstruccion.revistas.csic.es 


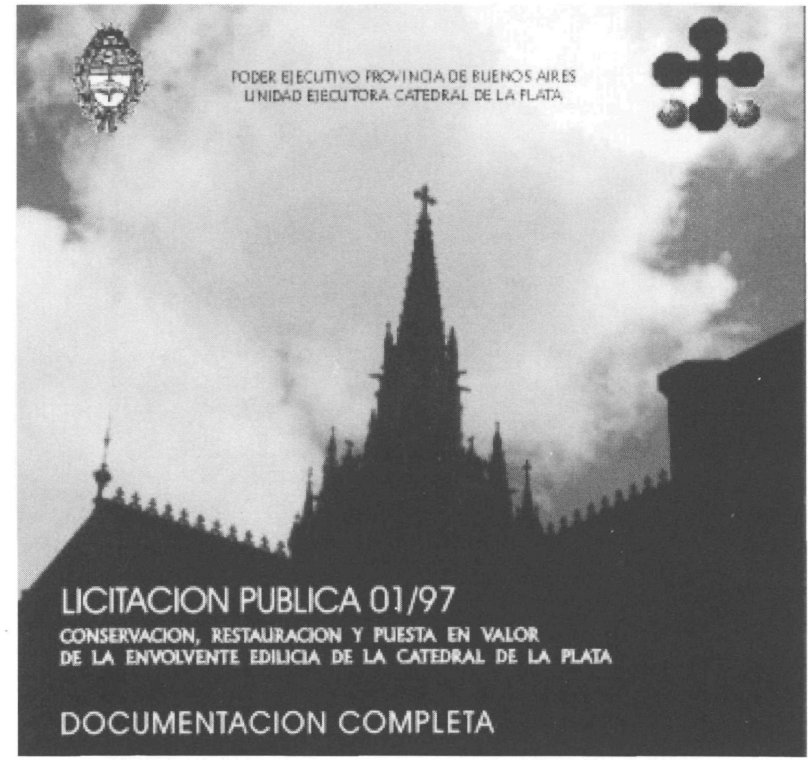

Foto 25

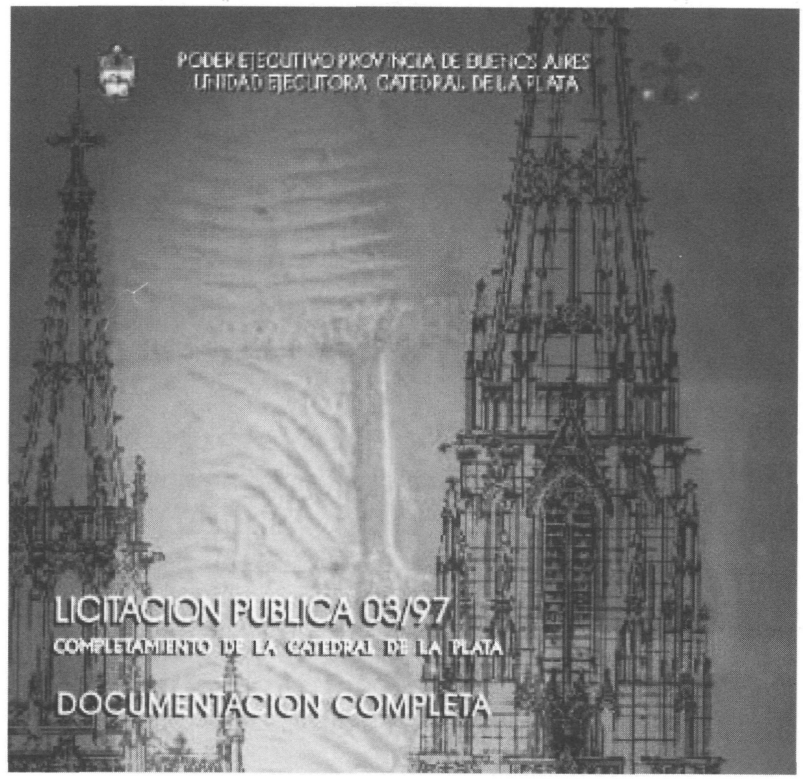

Foto 27

Fotos aéreas generales.

Planimetría y mosaico fotogramétrico.

Fotos de desajustes.

Planos y croquis.

Planillas y formularios.

Texto pliego de bases y condiciones.

Texto documentos internacionales sobre conservación del patrimonio.

(c) Consejo Superior de Investigaciones Científicas

Licencia Creative Commons 3.0 España (by-nc)

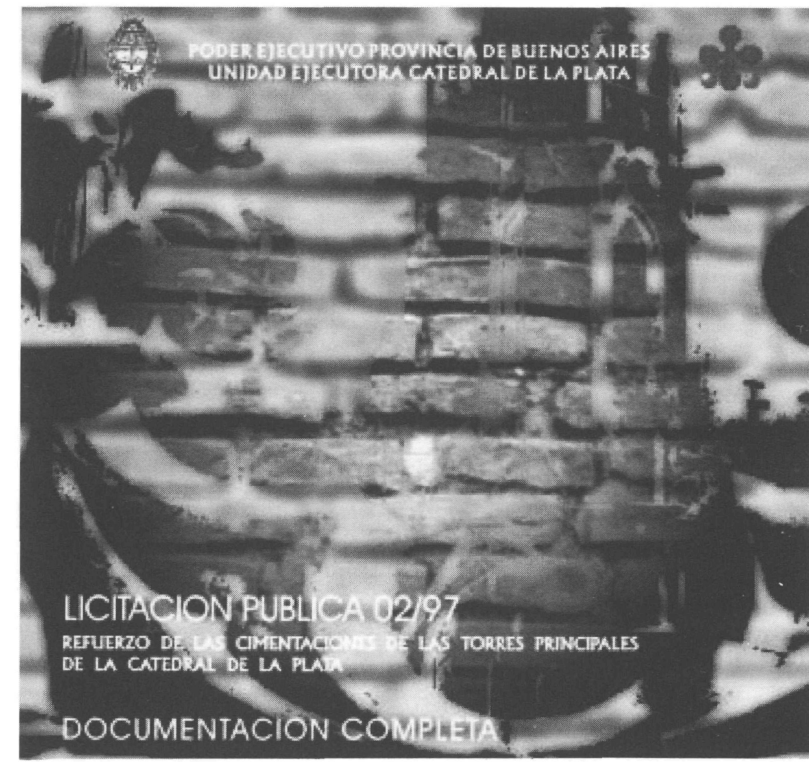

Foto 26

\section{V) Control posterior a la intervención}

\section{Monumento Inteligente}

Se trata de la aplicación de tecnología de última generación en la gestión del edificio, posterior a la puesta en valor. De modo que se puedan tener vinculados a una computadora central CCC una cantidad de sensores y analizadores de atmósfera interna, además de cámaras de circuito cerrado que permiten detectar posibles focos ígneos o intrusión de personas, así como la acción automática de extinción de incendios, con el apoyo de un grupo electrógeno para el accionamiento de bombas de impulsión de agua, el disparo de gases inertes o la iluminación de emergencia, de modo que permitan una adecuada protección del monumento.

\section{Sistema de control centralizado de las instalaciones}

Se trata de un sistema de Control Centralizado por Computadora que concentre las señales y las órdenes, incorporando también el control de los sistemas de incendio, control de accesos, guías del visitante, grupo electrógeno, etc.

\section{Equipamiento Hardware}

Se requiere la instalación de una red de Telecontrol y Telesupervisión, compuesta básicamente por:

\section{1) Sistema de control central:}

Proveerá las interfases de operación para efectuar la gestión integral de la red de Telecontrol y Telesupervisión, cubriendo las especificaciones de operatividad de un puesto de Control Centralizado por Computadora (CCC). http://informesdelaconstruccion.revistas.csic.es 


\section{2) Unidades Terminales Remotas (RTU):}

Para el control del Tablero General (TG), concentrando las señales de éste y las órdenes hacia el mismo.

Para todos los módulos de control de los sistemas de incendio, control de accesos, guía del visitante, grupo electrógeno (sólo el sistema de circuito cerrado de televisión actúa separado).

Cada RTU provee control local, teleseñalización y ejecución de mandos provenientes del CCC.

El Puesto Central de Comando se ha dividido en 2 equipos, independientes entre sí, pero físicamente contiguos en la Sala del Centro de Control Automático por Computadora.

- 1 equipo de control

- 1 equipo de seguridad

Será un sistema basado en PC y software de visualización y control con las siguientes características:

Sistema de observación, operación y control gráfico, orientado a objetos, desarrollado sobre la base de un sistema operativo multitarea.

Se destacan las siguientes funcionalidades:

Sistema gráfico de alta definición para el desarrollo y la operación con técnica de "menúes y ventanas", orientadas al funcionamiento del edificio.

Sistema de mensajes para la captura, archivo y representación selectiva en pantalla de eventos.

Sistema de protocolización ("Reports") para mensajes e informes configurables.

Salida a impresora en formatos libremente configurables.

Procesamiento en tiempo real.

Tiempos de actualización de variables parametrizable.

\section{Diseño del Software}

Los siguientos elementos gráficos componen la paleta de visualización:

- Campos de texto alfanuméricos.

- Campos de ingreso/salida de datos alfanuméricos.

- Gráficas de barras (horizontal/vertical, una/dos direcciones) con/sin ejes cartesianos.

\section{Sistema contra incendio}

\section{Prevención}

A fin de disminuir los riesgos de incendio y, además, aumentar las posibilidades de combatir, de modo efectivo, cualquier foco en sus comienzos, el contratista de las obras civiles habrá de mejorar algunas instalaciones, reemplazar la instalación eléctrica existente por una nueva, con la característica de antiexplosivo, para disminuir el riesgo de incendio eléctrico, siendo los aparatos de iluminación a instalar en el monumento, estancos.

\section{Detección y Extinción}

El sistema contra incendio consta de 2 funciones diferentes: la primera, trata de detectar un foco de incendio, en cualquier lugar, en sus primeros instantes; la segunda, combate ese incendio, antes incluso de que se expanda.

Ambas funciones son supervisadas y gobernadas por una central de incendio microprocesada, la cual estará ubicada en la oficina de CCC (Control Centralizado por Computadora). Esta central, de comunicación digital, tendrá las siguientes características:

- La comunicación entre la central y los dispositivos es de formato binario, con verificación de errores.

- Panel con teclado alfanumérico programable.

- Poseer no menos de 4 salidas para sirenas, supervisadas.

- Memoria no volátil de los últimos 500 eventos.

- Cada lazo será supervisado por cortocicuito y por circuito abierto.

- Baterías internas para suministro seguro, en caso de corte de energía.

- Indicación de pre-alarma y alarma.

- Posibilidad de lectura del estado de los sensores en tiempo real.

- Conformación de centrales en red, conexión directa.

En el medioevo -afirma el arquitecto Dino Bumbaru- la construcción de una catedral era una obra de toda una sociedad y de muchas generaciones. Estos edificios fueron también lugar de desarrollo tecnológico de primer nivel, donde el desafio de la dimensión, de la altura y de la luz fueron más que intenciones y se transformaron en objetivos claros para los maestros de construcción y la liturgia. En ese tiempo, la tecnología fue del mundo del saber empírico. Hoy, hablamos más 
de conocimiento científico, de un modo de tratar las informaciones y de integrar los procesos y los resultados de investigaciones de muchos campos disciplinar en una acción más amplia. Hablamos de conservación y de construcción, de este modo optimizamos el conocimiento con principios que conllevan al compromiso de nuestra generación de especialistas y de ciudadanos del futuro...

$\mathrm{Al}$ igual que muchas otras catedrales europeas, que se fueron completando a lo largo de los siglos y hoy son monumentos de la humanidad, la Catedral de La Plata, iniciada a fines del siglo XIX, se completa en la última década del siglo XX, para adquirir su fisonomía definitiva en el nuevo siglo XXI. Quizás así se materialicen estas palabras de Luigi Pareyson:

"La verdadera innovación ha de ser algo que merezca la pena que se haga, es decir, no lo nuevo por lo nuevo, sino lo original, y la verdadera conservación ha de ser algo que valga la pena mantener, no el pasado por el pasado, sino el pasado ejemplar. Así, la existencia del valor demuestra que la originalidad y la ejemplaridad coinciden y, por tanto, la innovación y la conservación pueden tener el mismo objeto y la posibilidad de un ejercicio simultáneo de conservación y de innovación es lo que realiza precisamente la tradición ".

\section{Ficha Técnica}

Promotor Unidad Ejecutora Catedral de La Plata, organismo de Secretaría General de la Gobernación. Provincia de Buenos Aires.

\section{Unidad Ejecutora Edificio Catedral de la Plata}

Presidente: Dr. Eduardo Di Marco

Vicepresidente: Arq. Néstor D. Nogueira

Director: Sr. Juan A. Gambier

\section{Área Técnica}

Secretario Técnico:

Equipo:

Dirección Técnica Estructuras:

Geotecnia:

Instalaciones:

Inspección de obra:

Seguridad en obra:

Electrónica:

Operadores de gráfica digital:

Relev. geotopográfico - fotogramétrico :

Deleg. ejecutivo de Fundación Catedral:

Investigación Histórica:

Empresas Constructoras:
Arq. Guillermo R. García

Arq. Jorge N. Bozzano.

Ing. José M. Jáuregui.

Ing. Roberto Igolnikow

Ing. Enrique Sánchez

Ing. Silvano Trevisán

Ing. Eduardo Núñez

Ing. Bernardo Hellmann

Ing. Amílcar Procchio

Ing. José María Uslengui

Ing. Jorge Ocaña

Ing. Alejandro Ben

Ing. Jorge Galocha

Jorge Arroyo

Arq. Manuel Hernández

Pablo Heffes

Martín Bai.

Agrim. Alejandro Márquez

Ing. César Crispiani.

Museo de la Catedral de La Plata.

Carner y Parma- Rol Ingeniería, Empresas Asociadä.

Perfomar S.A.

Ishtar S.A. 